\title{
Attitudes towards hunting in Polish society and the related impacts of hunting experience, socialisation and social networks
}

\author{
Małgorzata Krokowska-Paluszak ${ }^{1} \cdot{\text { Adrian } \text { Łukowski }^{2} \text { (D) - Anna Wierzbicka }}^{3}$ (D) - Arkadiusz Gruchała ${ }^{4}$ (D) \\ Jacek Sagan ${ }^{5} \cdot$ Maciej Skorupski $^{3}$ (D)
}

Received: 23 March 2020 / Revised: 16 July 2020 / Accepted: 4 August 2020 / Published online: 17 August 2020

(C) The Author(s) 2020

\begin{abstract}
In recent years, hunters in Poland have faced a low level of social acceptance. Scientists from the USA and Sweden have demonstrated that contact with hunters and game meat consumption is one of the decisive factors affecting the social acceptance of hunting. The aim of our study was to examine attitudes towards hunting (ATH) held by the non-hunting part of Polish society and to analyse factors influencing these perceptions. We hypothesised that Polish people have a generally negative ATH but that Polish people who have direct contact with hunters and eat game meat have a more positive ATH. During the study, we surveyed a randomly selected representative sample of 486 respondents. Based on nine statements defining non-hunters' perceptions, we determined ATH and then investigated its association with attitudinal items such as hunting experience, socialisation, social network and socio-demographic information. We found that most respondents $(61.7 \%)$ possessed an ATH that was at least slightly positive. Experience with hunting and hunters had a significant positive impact on ATH, and respondents who included game meat in their diet on a regular basis had a more positive ATH, as did respondents who participate in hunting. Socialisation and social network (having parents or friends who hunt/having a hunter in the household) were key positive influences on ATH. Conversely, the inability to visit a forest in their neighbourhood due to ongoing hunting had a significant negative impact on ATH. Different socio-demographic variables had a low impact on ATH. The results of this study show measurable steps towards increasing knowledge about social acceptance of hunting and can also be used as a strong argument in the discussion regarding the existence of sustainable hunting in Europe. We recommend several management implications, especially in a Polish context.
\end{abstract}

Keywords Game management $\cdot$ Society $\cdot$ Game meat $\cdot$ Likert scale $\cdot$ Poland

\section{Introduction}

Recently, hunting has become a popular topic, but it is not always presented objectively. Today, it is more common to

Anna Wierzbicka

anna.wierzbicka@up.poznan.pl

1 Poznan Regional Directorate of State Forests, Gajowa 8, 60-495 Poznań, Poland

2 Department of Silviculture, Poznań University of Life Sciences, Wojska Polskiego 69, 60-625 Poznań, Poland

3 Department of Game Management and Forest Protection, Poznań University of Life Sciences, Wojska Polskiego 71d, 60-625 Poznań, Poland

4 Faculty of Forestry, Warsaw University of Life Sciences - SGGW, Warsaw, Poland

5 Association of Foresters and Wood Technologists, Warsaw, Poland see active social movements presenting different attitudes towards hunting (ATH) (Adams et al. 2000). Many studies around the world have dealt with society's approach to hunting, particularly searching for factors determining acceptance or rejection of hunting (Lute et al. 2014). There are over seven million registered hunters in Europe (approx. $1 \%$ of residents), but the proportion of the population that participates in hunting varies among countries. In the Netherlands, $0.15 \%$ of the population hunts; $0.3 \%$ of the population hunts in Poland; $0.4 \%$ in Germany; $1.3 \%$ in the UK; $2.4 \%$ in Spain; approximately $3 \%$ of the combined population of Denmark, Norway and Sweden; and 8.5\% in Ireland (FACE 2010). In other regions of the world, the number of hunters in society is relatively higher: approximately $5 \%$ of the population in Canada, Australia, New Zealand and the USA hunts, ranging from 2 in the Pacific region of the USA to $12 \%$ in the central-western part of the country (Finch et al. 2014; Woods and Kerr 2010). The number (or proportion) of hunters in society is important 
because it is one of the basic factors determining the general acceptance of hunting. In addition, there are a number of factors pre-identified as being of importance to society's ATH. For example, people who accept hunting most often know at least one hunter personally (Ljung et al. 2012; Ljung et al. 2015). Hunting is also accepted by people who eat game meat (Butler et al. 2003; Ljung et al. 2012; Ljung et al. 2015).

Previous studies have shown that the acceptance of shooting animals is related to the awareness of harm they cause to fields and crops (Storm et al. 2007; Sijtsma et al. 2012). Society also accepts that hunting is carried out in situations where wild animals pose a threat to humans, involving threats from wild boars (Goulding and Roper 2002) or predators such as coyotes and wolves (Sponarski et al. 2015). People also accept hunting because of the threat of zoonotic diseases (Peterson et al. 2006) and the risk related to road accidents (Storm et al. 2007). The latest social studies among Poles show that knowledge regarding hunting is scarce and only a few individuals accept this concept (Balik 2015). Moreover, there are many different factors influencing this low level of acceptance, including hunting for sport and recreation (Ljung et al. 2012), participation of children in hunting and difficult access to the Polish Hunting Association. People are unaware of the economic importance of hunting and how critical it is to control the populations of individual species in situations when, for example, some species encroach upon urban areas and are vectors of diseases (Peterson et al. 2006).

Mitigation of the abovementioned conflicts between hunters and society can be achieved by filling the gap in formal education, such as by supporting sustainable hunting and forestry (Dzięciołowski 2011) and promoting game meat as a 'healthy meat' (Wierzbicka and Skorupski 2014). Great potential lies in conventional mass media (e.g. television, radio) but above all in new media, such as the Internet (Lukowski et al. 2016; Smarul et al. 2019). In our previous studies, the medium through which the respondents most often met with the topic of hunting and hunters was television, more specifically, TV news, series, nature programmes or advertisements (Łukowski et al. 2017). Those results undoubtedly indicate a large social group that may be additionally satisfied with, interested in and encouraged to search for and expand their knowledge about game management and hunting through new programmes or available programmes broadcast during prime time. However, a lack of knowledge is not the only factor that can impact acceptance of hunting. As mentioned before, studies in many countries have found that hunting is approved of by people who consume game meat (Butler et al. 2003; Ljung et al. 2012; Ljung et al. 2015), and a strong relationship exists between the frequency of game meat consumption and the acceptance of hunting. Game meat is considered high-quality meat, as distinguished by its nutritional values and taste (Hoffman and Wiklund 2006; Hutchison et al. 2010; Soriano et al. 2016; Wierzbicka and Skorupski 2014).
In the contemporary world, where people are seeking alternative food supplies, game meat is becoming a more attractive commodity and is more often recognised as a beneficial meat that possesses special health values (Barug et al. 2014; Kilar et al. 2015; Kwiecińska et al. 2017; Neethling et al. 2016) and more sustainable food with low carbon footprint (Fiala et al. 2020).

Research conducted in the USA and Sweden has confirmed that direct contact with hunters is another determinant of social acceptance of hunting (Ljung et al. 2012; MacKay and Campbell 2004). Those who accept hunting usually know at least one hunter personally (Ljung et al. 2012; Ljung et al. 2015) or have taken part in hunting at least once (Gangaas et al. 2013; Ljung et al. 2012; Ljung et al. 2015). There is no data about this topic from Poland.

We decided to investigate the factors determining the acceptance of hunting in Poland. We checked relationships between respondents ATH and their sex, age and place of residence (city, village), as well as if they had grown up in a home with hunters, had friends who hunt and included game meat in their diet. The aim of this study was to examine ATH held by the non-hunting part of Polish society and to analyse factors influencing this perception, particularly in relation to hunting experience (e.g. game meat consumption, hindered by hunt), socialisation (e.g. hunting by parents), social network (e.g. hunting by friends) and socio-demographic information (sex, age, etc.). We hypothesised that Polish people have a generally negative ATH but that people who have contact with hunters and eat game meat have a positive ATH.

\section{Materials and methods}

\section{Study area}

Poland is located in central-eastern Europe and covers an area of over $300,000 \mathrm{~km}^{2}$. The country's population is close to 38.5 million people, giving an average population density of 120 people per $\mathrm{km}^{2}$. To hunt in Poland, it is necessary to obtain a special licence after completing a course regarding knowledge and shooting skills. It is also necessary to be a member of the Polish Hunting Association.

In 2018, 126,583 people in Poland were eligible to hunt, and this number grows each year. Every year, the Polish Hunting Association registers approximately 4000 new members (source: www.pzl.gov.pl); however, hunters account for only $0.3 \%$ of the Polish population. In comparison, $13 \%$ of respondents in the USA had hunted in the year preceding the survey (Allen et al. 2013; NSSF 2011), and 3.3\% of inhabitants of Sweden are registered as hunters (Ljung et al. 2015).

In Poland, the most commonly hunted species are roe deer (Capreolus capreolus L.) and wild boar (Sus scrofa L.), and the most important species of trading game are red deer 
(Cervus elaphus L.) and wild boar. Game meat export from Poland in 2018 amounted to 57.7 thousand tons (GUS 2019).

\section{The questionnaire}

Data was collected from a research survey conducted by Swedish scientists (Ljung et al. 2012). We translated the questionnaire provided by Ljung. A sample of 486 Polish citizens was taken in 2016. Respondents filled out the questionnaire using the following methods: direct conversation with an interviewer recorded in paper form $(n=486)$. Samples were collected during a scientific picnic called the Warsaw University of Life Sciences Days (19-21 May 2016). We asked every 10th person that visited the Forest Faculty exhibition stand. Responders were asked to provide information regarding their age $(<20$ years, $21-30$ years, $31-40$ years, $41-$ 50 years, $>50$ years), sex (female, male), level of education (primary, secondary, higher), place of living $(<5000$ inhabitants, 5000-50,000 inhabitants, 50,000-150,000 inhabitants, $>500,000$ inhabitants). Respondents also provided information regarding their monthly net household income $(<500$ EUR, 500-1000 EUR, 1000-1500 EUR, > 1500 EUR). They were questioned on whether or not their parents (mother or father) were hunters or if any of their family members currently hunted (yes, no, I do not know), as well as if and how many of their friends hunted (almost everybody, more than half of them, half of them, a few, nobody, I do not know). Respondents were also asked if hunting activities in their immediate vicinity had ever stopped them from going to the forest (yes, no, I do not know). Respondents' feedback was used in data analysis only if they had not taken part in hunting in the 12 months prior to the survey, and they were described as a 'non-hunter'.

\section{Data analysis}

Results were combined based on nine statements defining the respondents' attitudes towards hunters and hunting (Table 1). We used Principal Component Analysis to assess the construct validity of items and Cronbach's $\alpha$ to measure the internal consistency (Vaske 2008). To allow the use of Likert's five-point scale, respondents were given the following five choices: I agree completely (2), agree somewhat (1), no opinion (0), disagree somewhat $(-1)$ and disagree completely $(-2)$. The setting scale ranged from -18 to 18 .

Using ANOVA and Tukey's test, we graded the differences in attitude among respondents that had never eaten game meat in their households, those who had eaten it only once or a couple of times in a year, those who ate game meat at least once a month and those who ate game meat once per week. The same tests were used for comparing how respondents evaluated their own ATH (on a five-level Likert scale), with a scale range ( -18 up to 18 ) based on the previous nine answers that defined the attitude towards hunters and hunting.

We used a $t$ test to compare differences in the attitude scores among categories of respondents, and we used Cohen's $d$ to investigate effect size, with cut-off levels of $d>0.1$ for a small effect, $d>0.3$ for a medium effect and $d>0.6$ for a large effect (Cohen 1992). For the purpose of this analysis, respondent's age was divided into two classes, $\leq$ 40 years and $>40$ years. Level of qualification (education) was simplified to higher and below higher. The respondents were divided based on place of residence into two groups: places with $<50,000$ inhabitants and places with $>50,000$ inhabitants. In the above analysis, three multi-choice variables (questions regarding how many friends hunt, the use of game in the household and whether hunting in the immediate vicinity has interrupted visits to the forest) were converted into binary variables (yes, no).

\section{Results}

In total, we conducted a survey of 486 respondents, none of which were excluded in further analysis, because they had not hunted in the last 12 months. Thus for further analysis, we used the responses of all respondents.

\section{Characteristics of respondents}

Among non-hunting respondents, the majority were women aged between 21 and 30 years (57\%). Approximately onethird of respondents (37\%) lived in places with 5000-50,000 inhabitants. The majority of non-hunting respondents had never consumed game meat (59\%). The remaining respondents $(41 \%)$ had eaten game meat at least once in their life, but used it sporadically: once a year $(81 \%)$, once a month $(14 \%)$ or once a week $(5 \%)$. More than a half of nonhunting respondents $(57 \%)$ did not have friends who hunt or were not aware if any of their friends hunt. Only $1 \%$ of respondents stated that all their friends hunt, whereas $2 \%$ said more than a half of their friends hunt, $7 \%$ said half of their friends hunt and $37 \%$ of respondents had several friends who hunt. Nearly all respondents were raised by non-hunting parents. Only $8 \%$ were raised by a father who hunted and $0.6 \%$ by a mother who hunted. Hunting in the immediate vicinity of their living place had prevented $17 \%$ of non-hunting respondents from going to the forest on at least one occasion.

Among the non-hunting respondents who had eaten game meat at least once $(n=200 ; 41 \%)$, more than half $(84 \%)$ had a few friends who hunt. Only $2 \%$ of respondents who had eaten game meat at least once said that nearly all of their friends hunt, whereas $16 \%$ of those respondents stated that approximately half of their friends hunt, nearly $12 \%$ did not have hunting friends and 5\% did not know if their friends hunt. 
Table 1 Opinions of non-hunters regarding nine items related to attitudes towards hunting and hunters

\begin{tabular}{|c|c|c|c|c|c|c|c|c|}
\hline & Items & N1 & $\begin{array}{l}\% \\
\text { Agree }\end{array}$ & $\mathrm{N} 2$ & $\begin{array}{l}\% \\
\text { Disagree }\end{array}$ & N3 & $\begin{array}{l}\% \text { No } \\
\text { opinion }\end{array}$ & $\begin{array}{l}\text { Factor loading } \\
\text { PC1 }\end{array}$ \\
\hline 1 & I regard any kind of sport and recreational hunting as cruel to animals & 272 & 57 & 141 & 29 & 73 & 14 & 0.64 \\
\hline 2 & $\begin{array}{l}\text { I see little wrong with harvesting animals for their meat, as long as the animal is } \\
\text { not endangered }\end{array}$ & 316 & 65 & 118 & 24 & 90 & 11 & 0.57 \\
\hline 3 & Hunting helps keep nature in balance & 380 & 78 & 67 & 14 & 39 & 8 & 0.66 \\
\hline 4 & Hunters often ignore safety rules & 189 & 39 & 118 & 24 & 179 & 37 & 0.67 \\
\hline 5 & Most hunters are well-prepared when they go hunting & 274 & 56 & 66 & 14 & 146 & 30 & 0.63 \\
\hline 6 & Hunters often harm animals, which then die slow and painful deaths & 168 & 35 & 161 & 33 & 157 & 32 & 0.70 \\
\hline 7 & Hunters are properly trained and follow hunting regulations & 199 & 41 & 111 & 23 & 176 & 36 & 0.57 \\
\hline 8 & Hunting is an important rural tradition & 186 & 38 & 151 & 31 & 149 & 31 & 0.58 \\
\hline 9 & I do not like people who hunt & 233 & 48 & 95 & 20 & 158 & 32 & 0.71 \\
\hline
\end{tabular}

Loadings (from Principal Component Analysis) of each item on principal component one (PC1) are also shown. Questions in bold specifically investigated negative attitudes towards hunting. Data was collected in 2016 from a random sample of 486 Polish residents. Non-hunters are defined as persons who had not hunted in the 12 months prior to the survey

\section{Attitudes towards hunting}

Non-hunting respondents recognised that hunting contributes to keeping a natural balance in the environment (Table 1), but hunting was not recognised as a countryside tradition. Half of the respondents admitted that the majority of hunters are very well prepared for hunting (it means they have knowledge and skills needed for hunting according to Polish law). Two-fifths of respondents considered hunters to be well-educated people who obey the hunting law, and another two-fifths of the respondents complained about hunters ignoring basic principles related with safety. Approximately 57\% of respondents believed that hunting for sport purposes is an act of cruelty.

The nine questionnaire items (Cronbach's $\alpha=0.82$ ) had similar factor loadings (ranging from 0.57 to 0.71 ) on principal component 1 (PC1), which was the only component with an eigenvalue $>1$ (3.71). PC1 explained $42 \%$ of the variance, and thus we judged that it was sufficient to use this principal component only. PC1 was highly correlated with the attitude score $(r=0.996, n=486, P<0.001)$, which is easier to interpret than $\mathrm{PC} 1$. We therefore concluded that the attitude score is a suitable measure of ATH. Most respondents (61.7\%) held an ATH that was at least slightly positive (i.e. had attitude score $\geq 1$; Fig. 1); mean attitude score was $2.6(n=486$, $\mathrm{SD}=7.4)$.

Score results based on the nine questions defining attitude towards hunters and hunting were correlated with ATH, as personally assessed by each respondent $\left(F_{4,481}=97.91\right.$, $P<0.0001$; Fig. 2).

Experience with hunting and hunters had a significant impact on the attitude score (Table 2). Respondents who included game meat in their diet on a regular basis had attitude
Fig. 1 Histogram showing the proportion of non-hunters (respondents who had not hunted in the 12 months prior to the survey) with each attitude score. Attitude score was based on nine attitudinal items regarding hunting and hunters and ranged from -18 to 18 (see Table 1). Data was collected in 2016 from a random sample of 486 Polish residents

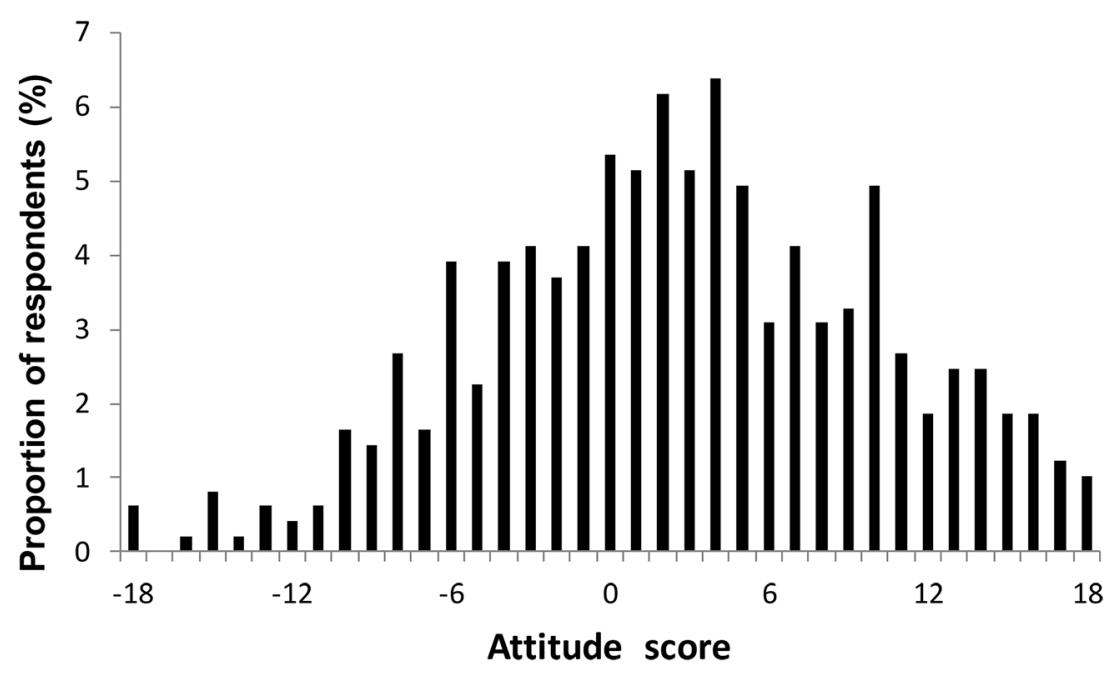


scores that were, on average, 6.1 points greater than those of respondents who had never eaten game meat before. A similar situation was observed among respondents who had participated in hunting - their average attitude score was 4.8 points greater than that of respondents who had never taken part in hunting before. In addition, the possibility of not being able to visit a neighbourhood forest due to ongoing hunting had a significant negative impact on the attitude score. Significant attitudinal differences were observed among non-hunters who consumed game meat (no matter how often they consume) and those who did not consume game meat at all $\left(F_{4,481}=\right.$ 33.98, $P<0.0001$; Fig. 3).

Socialisation and networking, including family and friends, had essential influences on the attitude score (Table 2). Both having father or friends who hunt and having a hunter in the household had positive effects on the attitude score. Respondents who grew up with parents who hunted had average attitude scores of 5.4 (hunting mother) and 6.5 (hunting father) more points than those of respondents who had nonhunting parents; however the 'mother that hunted' item had a small and non-significant effect. A similar result was obtained in the case of respondents with hunters in their household (4.7 points greater attitude score). Respondents who had friends who hunt had an attitude score that was, on average, 7.6 points greater than that of respondents who did not have friends who hunt.

Socio-demographic variables had a low impact on attitude towards hunters and hunting (Table 2). Education background, place of living and monthly income had no influence on the attitude score. Only sex and age (marginally) were statistically important, but all appeared to cause medium to small effects. Men and respondents who were $\leq 40$ years of age had, on average, 2.4 and 1.3 more points on the attitude scale, respectively, than did their counterparts.

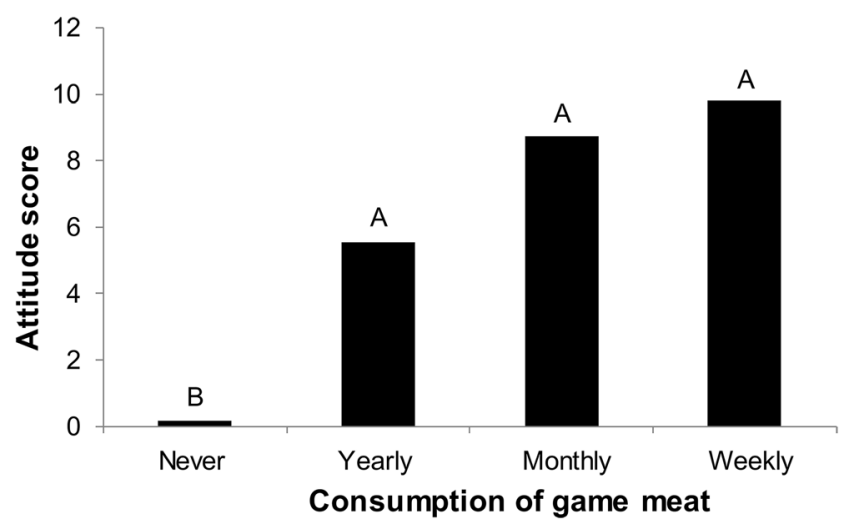

Fig. 2 Mean attitude scores of non-hunters (respondents who had not hunted in the 12 months prior to the survey) in relation to their personal attitude towards hunting. Different letters indicate a statistically significant difference based on the post hoc non-parametric comparisons for each pair by Wilcoxon method $(P<0.05)$

\section{Discussion}

Our main results show that Poles who do not hunt hold a slightly positive ATH, confirming previous research concerning the level of hunting acceptance in Poland (Balik 2015). Until now, there was no data about the reasons for this situation. The most significant determinant of positive ATH was having a friend who hunts and a father who hunted. This confirms the opinions of other authors from various countries, who have claimed that attitude towards hunters and hunting is influenced by parents (Backman and Wright 1993; Ljung et al. 2012; Stedman and Heberlein 2001). A positive ATH can also be related to living in a household where at least one person hunts, as well as being familiar with people that do so on a regular basis. This statement is a part of the current results of research both in Europe and other parts of the world. We verified and confirmed the research hypothesis put forward by Heberlein and Ericsson (2005), who suggested that having a relationship with a hunter can cause a positive evaluation of hunting. Someone who accepts hunting most often knows at least one hunter personally (Gamborg and SøndergaardJensen 2017; Ljung et al. 2012; Ljung et al. 2015). Participation in the hunt also has a significant effect on attitude towards hunting and hunters. Poles do not differ from other nations in this regard.

It is known that in countries where there are a high percentage of people who hunt, society is characterised by a high level of acceptance for hunting (NSSF 2011). For many reasons, mainly related to the costly, complicated, long-term process of acquiring hunting rights and the lack of media activities promoting hunting, hunting in Poland is a niche occupation and does not receive much interest $(0.3 \%$ of the population hunts; (FACE 2010). Our results indicate that with so little interest in hunting, the attitude is slightly positive (Fig. 1). It should be noted, however, that some of our results, as well as increasingly visible social behaviour in everyday life (e.g. organising via Facebook to mutually disrupt legal hunting in forests around Polish cities), show a negative ATH in certain situations. The situation is completely different in the USA, where as many as $13 \%$ of respondents to a survey had hunted in the year preceding the survey (NSSF 2011; Allen et al. 2013) and up to 74\% of respondents accepted hunting (Allen et al. 2013). A model of Swedish hunting is worth exploring and implementing in the Polish context (Eriksson et al. 2006). In Sweden, approx. 3.3\% of residents are registered as hunters (Ljung et al. 2015), and $87 \%$ of the population has a positive ATH (FACE 2010).

Another variable in this study that was important in shaping ATH was the frequency of game meat consumption. This also confirms the results of research by other authors who have found that in the USA and Scandinavia to be true (Blascovich and Metcalf 2019; Butler et al. 2003; Gamborg and Søndergaard-Jensen 2017; Ljung et al. 2012; Ljung et al. 
Table 2 Average attitude scores of non-hunters (persons who had not hunted in the 12 months prior to the survey; $n=486$ ) in relation to their sociodemographic characteristics

\begin{tabular}{|c|c|c|c|c|c|c|}
\hline \multirow[t]{2}{*}{ Attitudinal items } & \multicolumn{2}{|c|}{ Attitude score } & \multirow[t]{2}{*}{$P$ value } & \multirow[t]{2}{*}{$t$} & \multirow[t]{2}{*}{ Cohen's $d$} & \multirow[t]{2}{*}{ Effect size } \\
\hline & Yes & No & & & & \\
\hline \multicolumn{7}{|l|}{ Hunting experience } \\
\hline Eat game (yes; no) & 6.2 & 0.1 & $<0.0001$ & 9.61 & 0.88 & Large \\
\hline Hindered by hunt (yes; no) & -4.1 & 4.0 & $<0.0001$ & 8.90 & 1.18 & Large \\
\hline Hunted before (yes; no) & 7.1 & 2.3 & 0.0005 & 3.53 & 0.65 & Large \\
\hline \multicolumn{7}{|l|}{ Socialisation } \\
\hline Mother that hunted (yes; no) & 8.0 & 2.6 & 0.2702 & 1.11 & 0.12 & Small \\
\hline Father that hunted (yes; no) & 8.6 & 2.1 & $<0.0001$ & 8.88 & 0.90 & Large \\
\hline \multicolumn{7}{|l|}{ Social network } \\
\hline Hunter in household (yes; no) & 6.6 & 1.9 & $<0.0001$ & 5.13 & 0.64 & Large \\
\hline Friends that hunt (yes; no) & 5.6 & -2.0 & $<0.0001$ & 11.46 & 1.16 & Large \\
\hline \multicolumn{7}{|l|}{ Socio-demographic information } \\
\hline Sex (man; woman) & 4.0 & 1.6 & 0.0005 & 3.52 & 0.32 & Medium \\
\hline Age $(\leq 40 ;>40)$ & 3.1 & 1.8 & 0.0580 & 1.90 & 0.18 & Small \\
\hline Education (university; other) & 2.6 & 2.6 & 0.9732 & 0.03 & 0.01 & ------ \\
\hline Current place of residence ( $\leq 50,000$ residents; $>50,000$ residents $)$ & 2.7 & 2.4 & 0.7212 & 0.36 & 0.03 & ----- \\
\hline Household income $(\leq 1000$ Euros; $>1000$ Euros $)$ & 2.6 & 2.9 & 0.7584 & 0.31 & 0.04 & ------ \\
\hline
\end{tabular}

The attitude score was calculated based on nine attitudinal items, and the attitude scale was centred on 0 (ranging from -18 to 18 )

2015). It seems reasonable to assume that eating game meat also has a social dimension. In Poland, non-hunters have two ways by which to obtain game meat: obtain it from friends who hunt or buy it in a shop for a relatively high price (the availability of game meat in shops is limited). Thus, consumption of game meat in Poland is low, and access to game meat is not common in the contrary to other European countries

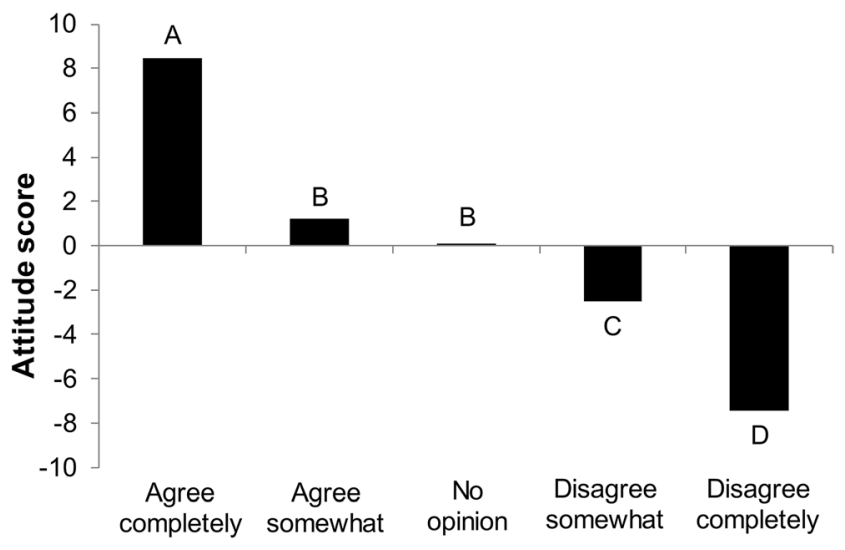

Attitude towards hunting

Fig. 3 Mean attitude scores of non-hunters (respondents who had not hunted in the 12 months prior to the survey) in relation to how frequently they consumed game meat. Different letters indicate a statistically significant difference based on the post hoc non-parametric comparisons for each pair by Wilcoxon method $(P<0.05)$
(Tomasevic et al. 2018). Game meat is considered an exclusive commodity, and due to its high price, it is a niche product in the retail trade (Barug et al. 2014; Simińska et al. 2011; Popczyk 2012). The average Pole consumes $0.08 \mathrm{~kg}$ of game meat per year (Balcerzak and Popczyk 2017) but could eat close to $2 \mathrm{~kg}$ (Popczyk 2012). Poles would eat more game meat if it would be more available (Kwiecińska et al. 2017). In comparison, in Sweden, where game meat consumption is common, approximately $70 \%$ of Swedes report consumption of one or more meals involving game meat per year (Ericsson and Heberlein 2002). Average consumption of game meat in European countries is as follows: Czechia $1.1 \mathrm{~kg}$ per year, Sweden $1.8 \mathrm{~kg}$ per year Norway $3.3 \mathrm{~kg}$ per year and up to $8.4 \mathrm{~kg}$ per year in some parts of Italy (Tomasevic et al. 2018).

Another issue related to ATH is the purpose of huntinghunting for meat or recreational/hobby hunting. Poles have a generally neutral approach to hunting; however, hunting for meat is accepted by $63 \%$ of the population (KrokowskaPaluszak et al. unpublished data), whereas hunting for recreation is not accepted by $57 \%$ (Table 1). Canadian and Swedish respondents, like those in Poland, do not accept sport hunting (MacKay and Campbell 2004; Ljung et al. 2015). A high percentage of people, who support hunting for meat, may result from the belief that hunting is a way to obtain healthy food (Butler et al. 2003). In the Polish context, it would be desirable to increase the availability of 
game meat. Especially that in other European countries where game meat consumption is much higher, respondents were buying meat mostly (44\%) from hunters or in shops (Tomasevic et al. 2018).

Another important factor influencing opinions regarding hunting is whether or not the possibility of visiting neighbourhood forests is hindered due to ongoing hunting. Respondents who had experienced such situations held a more negative ATH (Table 2). This appears to be an indication for Polish hunters to pay more attention to the dates and places when and where they hunt, which should be determined by consulting with local communities. The needs and interests of residents when using forest resources are considered equal to the needs of hunters resulting from sustainable hunting (Milbourne 2003).

Indubitably, the assessment of social attitude is important because it helps in determining and understanding factors that influence the social acceptance or opposition of certain phenomena (Minnis 1998). In the case of our research, this assessment also allowed us to identify problems, as well as indicate the need to take actions aimed at increasing the acceptance of hunting in society and building a positive social ATH. We recommend several management implications, such as increasing the distribution and availability of game meat as it could directly influence the acceptance of hunting in a positive way. In addition, it is expected that an increase in the number of hunters may strengthen the social links between non-hunters and hunters, who are promoters of a favourable ATH.

Authors' contributions Conceptualization, Arkadiusz Gruchała, Jacek Sagan and Maciej Skorupski; formal analysis, Adrian Łukowski; investigation, Małgorzata Krokowska-Paluszak and Adrian Łukowski; methodology, Małgorzata Krokowska-Paluszak and Anna Wierzbicka; supervision, Anna Wierzbicka and Maciej Skorupski; visualisation, Adrian Łukowski; writing (original draft), Małgorzata Krokowska-Paluszak; writing (review and editing) Adrian Łukowski, Anna Wierzbicka, Arkadiusz Gruchała, Jacek Sagan and Maciej Skorupski. All authors read and approved the final manuscript.

Data availability The datasets generated during and/or analysed during the current study are available from the corresponding author on a reasonable request.

\section{Compliance with ethical standards}

Conflicts of interest The authors declare that they have no conflict of interest.

Ethics approval Not applicable.

Consent to participate Not applicable.

Consent for publication Not applicable.

Code availability Not applicable.
Open Access This article is licensed under a Creative Commons Attribution 4.0 International License, which permits use, sharing, adaptation, distribution and reproduction in any medium or format, as long as you give appropriate credit to the original author(s) and the source, provide a link to the Creative Commons licence, and indicate if changes were made. The images or other third party material in this article are included in the article's Creative Commons licence, unless indicated otherwise in a credit line to the material. If material is not included in the article's Creative Commons licence and your intended use is not permitted by statutory regulation or exceeds the permitted use, you will need to obtain permission directly from the copyright holder. To view a copy of this licence, visit http://creativecommons.org/licenses/by/4.0/.

\section{References}

Adams CE, Wilkins N, Cooke JL (2000) A place to hunt: organizational changes in recreational hunting, using Texas as a case study. Wildlife Soc B 28(4):788-796. https://doi.org/10.2307/3783833

Allen T, Southwick R, Howlett D (2013) Hunting in America: an economic force for conservation. Newtown, USA. Available from: https://www.fs.fed.us/biology/resources/pubs/wildlife/ HuntingEconomicImpacts-NSSF-Southwick.pdf (accessed on 15 of March 2018)

Backman SJ, Wright BA (1993) An explanatory study of the relationship of attitude and the perception of constraints to hunting. J. Park Recreat Adm 11:1-16

Balcerzak M, Popczyk B (2017) Economic aspects of hunting. In: Lachowski K (ed) Game meet. FOREST, Warsaw, Poland, pp 10 19 (in Polish)

Balik B (2015) Social perception of hunting in Poland and Europe. In: Gil W (ed) Hunting in sustainable forest management. Winter Forest School at the Forestry Research Institute, VII Session, Sekocin Stary, Poland, pp 246-258 (in Polish)

Barug AJ, Iwanicka A, Gruszecki TM (2014) Chosen attitudes and behaviours of Polish final buyers related to niche food. Roczniki Naukowe Stowarzyszenia Ekonomistów Rolnictwa i Agrobiznesu 16:22-27 (in Polish)

Blascovich GM, Metcalf AL (2019) Improving non-hunters' attitudes toward hunting. Hum Dimens Wildl 24(5):480-487. https://doi. org/10.1080/10871209.2019.1605636

Butler JS, Shanahan J, Decker DJ (2003) Public attitudes toward wildlife are changing: a trend analysis of New York residents. Wildlife Soc B 31(4):1027-1036 http://www.jstor.org/stable/3784448

Cohen J (1992) A power primer. Psychol Bull 112:155-159

Dzięciołowski R (2011) Idea of sustainable hunting across the world. Ann Warsaw Univ of Life Sc. - SGGW Anim Sci 50:3-10 (in Polish)

Ericsson G, Heberlein TA (2002) “Jägare talar naturens språk” (Hunters Speak Nature's Language). A comparison of outdoor activities and attitudes toward wildlife among Swedish hunters and the general public. Zeitschrift für Jagdwissenschaft 48:301-308. https://doi. org/10.1007/BF02192422

Eriksson T, Andersson J, Byström P, Hörnell-Willebrand M, Laitila T, Sandström C, Willebrand T (2006) Fish and wildlife in the Swedish mountain region: resources, use and management. Int J Biodivers Sci Ecosyst Serv Manag 2(4):334-342. https://doi.org/10.1080/ 17451590609618154

FACE (2010) Annual Report 2009-2010. Available from: http://www. face.eu/sites/deafult/files/attachments/data hunters-region sept 2010.pdf (accessed on 15 of March 2018)

Fiala M, Marveggio D, Vigano R, Demartini E, Nonini L, Gaviglio A (2020) LCA and wild animals: results from wild deer culled in a 
northern Italy hunting district. J Clean Prod 244:118667. https://oi. org/10.1016/j.jclepro.2019.118667

Finch N, Murray P, Hoy J, Baxter G (2014) Expenditure and motivation of Australian recreational hunters. Wildlife Res 41(1):76-83. https:// doi.org/10.1071/WR13171

Gamborg C, Søndergaard-Jensen F (2017) Attitudes towards recreational hunting: a quantitative survey of the general public in Denmark. J Outdoor Recreat Tour 17:20-28. https://doi.org/10.1016/j.jort.2016. 12.002

Gangaas KE, Kaltenborn BP, Andreassen HP (2013) Geo-spatial aspects of acceptance of illegal hunting of large carnivores in Scandinavia. PLOS One 8(7):e68849. https://doi.org/10.1371/journal.pone. 0068849

Goulding MJ, Roper TJ (2002) Press responses to the presence of freeliving wild boar (Sus scrofa) in southern England. Mammal Rev 32(4):272-282. https://doi.org/10.1046/j.1365-2907.2002.00109.x

GUS. Forestry (2019) Central Statistical Office. Warsaw, Poland. Available from: https://stat.gov.pl/files/gfx/portalinformacyjny/pl/ defaultaktualnosci/5510/1/13/1/lesnictwo_2017.pdf (accessed on 08 of March 2020)

Heberlein TA, Ericsson G (2005) Ties to the countryside: accounting for urbanites attitudes toward hunting wolves and wildlife. Hum Dimens Wildl 10:213-227. https://doi.org/10.1080/ 10871200591003454

Hoffman LC, Wiklund E (2006) Game and venison - meat for the modern consumer. Meat Sci 74:197-208. https://doi.org/10.1016/j. meatsci.2006.04.005

Hutchison CL, Mulley RC, Wiklund E, Flesch JS (2010) Consumer evaluation of venison sensory quality: effects of sex, body condition score and carcass suspension method. Meat Sci 86:113-116. https://doi.org/10.1016/j.meatsci.2010.04.031

Kilar J, Ruda M, Kilar M (2015) Consumer interest in venison. In: Karwowska M, Gustaw W (eds) Trends in human nutrition. Wydawnictwo Naukowe PTTŻ, Kraków, Poland, pp 101-111

Kwiecińska K, Kosicka-Gębska M, Gębski J, Gutkowska K (2017) Prediction of the conditions for the consumption of game by polish consumers. Meat Sci 131:28-33. https://doi.org/10.1016/j.meatsci. 2017.04.038

Ljung PE, Riley SJ, Heberlein TA, Ericsson G (2012) Eat prey and love: game-meat consumption and attitudes toward hunting. Wildlife Soc B 36(4):669-675. https://doi.org/10.1002/wsb.208

Ljung PE, Riley SJ, Ericsson G (2015) Game meat consumption feeds urban support of traditional use of natural resources. Soc Natur Resour 28:657-669. https://doi.org/10.1080/08941920.2014. 933929

Łukowski A, Opalińska P, Wierzbicka A (2016) Activity of forestry divisions in social media on the example of the "Facebook". Studia i Materiały CEPL w Rogowie 47:209-216 (in Polish)

Łukowski A, Krokowska-Paluszak M, Opalińska P, Błasiak A, Wierzbicka A, Skorupski M, Sagan J, Gruchała A, Tomusiak R (2017) Television as a source of information about game management - social research. Studia i Materiały CEPL w Rogowie 50: 184-191 (in Polish)

Lute ML, Bump A, Gore ML (2014) Identity-driven differences in stakeholder concerns about hunting wolves. PLoS ONE 9(12):e114460. https://doi.org/10.1371/journal.pone.0114460

MacKay KJ, Campbell JM (2004) An examination of attitudes toward hunting as a tourism product. Tourism Manage 25(5):443-452. https://doi.org/10.1016/S0261-5177(03)00127-4

Milbourne P (2003) Hunting ruralities: nature, society and culture in 'hunt countries' of England and Wales. J Rural Stud 19(2):157-171. https://doi.org/10.1016/S0743-0167(02)00054-2
Minnis DL (1998) The opposition to hunting: a typology of beliefs. In: Transactions of the North American Wildlife and Natural Resources Conference. Wildlife Management Institute 62:346-360

Neethling J, Hoffman LC, Muller M (2016) Factors influencing the flavor of game meat: a review. Meat Sci 113:139-153. https://doi.org/10. 1016/j.meatsci.2015.11.022

NSSF (2011) Americans attitudes toward hunting, fishing and target shooting. National Shooting Sports Foundation. Newtown, USA. Available from: https://pl.scribd.com/document/98647673/NSSFAmerican-s-Attitudes-towards-Hunting-Fishing-and-TargetShooting-2011 (accessed on 15 of March 2018)

Peterson MN, Mertig AG, Liu J (2006) Effects of zoonotic disease attributes on public attitudes towards wildlife management. J Wildl Manage 70(6):1746-1753. https://doi.org/10.2193/0022541X(2006)70[1746:EOZDAO]2.0.CO;2

Popczyk B (2012) Problems with wild game trade. In: Gwiazdowicz DJ (ed) Problems of modern hunting in Poland. PTL, Poznań, Poland, pp 137-150 (in Polish)

Sijtsma MTJ, Vaske JJ, Jacobs MH (2012) Acceptability of lethal control of wildlife that damage agriculture in the Netherlands. Soc Natur Resour 25:1308-1323. https://doi.org/10.1080/08941920.2012. 684850

Simińska E, Bernacka H, Sadowski T (2011) The situation on the world and domestic game market. Annals of Warsaw University of Live Sciences - SGGW Animal Sci 50:89-96

Smarul N, Tomczak K, Wierzbicka A, Łukowski A (2019) Possibilities and level of use of Facebook by the State Forests. Sylwan 163(7): 542-550. https://doi.org/10.26202/sylwan.2018154

Soriano A, Montoro V, Vicente J, Sánchez-Migallón BF (2016) Influence of evisceration time and carcass ageing conditions on wild venison quality. Preliminary study. Meat Sci 114:130-136. https://doi.org/ 10.1016/j.meatsci.2015.12.021

Sponarski CC, Vaske JJ, Bath AJ (2015) The role of cognitions and emotions in human-coyote interactions. Hum Dimens Wildl 20: 238-254. https://doi.org/10.1080/10871209.2015.1010756

Stedman RC, Heberlein TA (2001) Hunting and rural socialization: contingent effects of the rural setting on hunting participation. Rural Sociol 66:599-617. https://doi.org/10.1111/j.1549-0831.2001. tb00086.x

Storm DJ, Nielson CK, Shauber EM, Woolf A (2007) Deer - human conflict and hunter access in an exurban landscape. Hum-Wildl Confl 1:53-59

Tomasevic I, Novakovic S, Solowiej B, Zdolec N, Skunca D, Krocka M, Nedomova S, Kolaj R, Aleksiev G, Djekic I (2018) Consumers' perceptions, attitudes and perceived quality of game meat in ten European countries. Meat Sci. 142:5-13. https://doi.org/10.1016/j. meatsci.2018.03.016

Vaske J (2008) Survey research and analysis: applications in parks, recreation and human dimensions. Venture Publishing, State College

Wierzbicka A, Skorupski M (2014) Game meet as a source of healthy food - problems and perspectives. Studia i Materiały CEPL w Rogowie 38(1):171-174 (in Polish)

Woods A, Kerr GN (2010) Recreational game hunting: motivations, satisfactions and participation. Land, Environment and People Report No. 18. Lincoln University, Canterbury, New Zealand. Available from: https://hdl.handle.net/10182/2128 (accessed on 15 of March 2018)

Publisher's note Springer Nature remains neutral with regard to jurisdictional claims in published maps and institutional affiliations. 